\title{
FORMATION OF NORMS FOR THE FUTURE TRANSLATORS PROFESSIONAL BEHAVIOR AT THE PROFESSIONAL RESEARCH LESSON IN THE HIGHER EDUCATION SYSTEM
}

(C) 2016

A.N. Ryblova, doctor of pedagogical sciences, professor, professor of Linguistics and Intercultural Communication Department Russian New University, Moscow (Russia)

Abstract. The article touches upon an urgent problem to improve the quality of the personnel practical training, for which the author offers solutions to shape norms for future translators professional behavior at the professional research lesson in the higher education system. On the basis of theoretical and methodological analysis of the works of domestic and foreign scientists the author considers it necessary to modernize the technology of organizational process on the basis of needs of employers and individual needs of students. At the same time the main activity of students at the professional research lesson should be autonomous cognitive activity focused on their future profession, the realization of which the article offers a detailed description of different types of students' group activities aimed at processing foreign language professionally significant information in professionally given situations under the supervision of a teacher at the professional research lesson. The author, based on many years of experience teaching activities in the university confirms that this type of lesson promotes the acquisition by students of professional experience, the formation of organizational and production skills and provides personal development training, which ultimately contributes to the intensive and high-quality practical training of translators in the system of higher education.

Keywords: norms of professional behavior; future translators; professional research lesson; higher education system; practical training; professionals of international level; autonomous cognitive activity; focus on the future profession; technology modernization of organizational process; types of group activity; foreign language professionally significant information; professionally given situations; under the teacher supervision; experience acquisition; needs of employers; individual needs of students; formation of organizational and production skills.

удК 37.015.3:17.023.6

\section{МОРАЛЬНО-ЭТИЧЕСКИЕ ПРИНЦИПЫ КАК ПРЕДМЕТ ПЕДАГОГИЧЕСКОЙ РЕФЛЕКСИИ}

(C) 2016
А.И. Салов, кандидат педагогических наук, доцент, ректор
Академия сочиального управления, Москва (Россия)

\begin{abstract}
Аннотация. В статье обосновывается, что морально-этические принципы ориентируют учителя на совместный с учащимися поиск смысла жизни, который проясняет им отношения с миром, жизненный мир педагога и учащихся, существует в их сознании в виде образа мира и регулирует их совместную деятельность в соответствии с логикой жизненной необходимости - Мир на Земле. Объясняется, что подлинная мораль считает человека и его жизнь высшими моральными ценностями, в которых формулируются морально-этические принципы, предписывающие выработку стратегии нравственной жизни; обосновывается, что от правильного понимания ценностей зависит нравственность человека, его поступки, взгляды, оценки, цели и мотивы деятельности и взаимодействия с миром и с людьми; делаются пояснения относительно категорий «добродетель», «благо», в терминах которых формулируются морально-этические принципы; приводятся значения категорий «добродетель» и «благо»; объясняется, почему добродетели научить нельзя, что добродетели не являются врожденным, а потому они воспитываются; показывается, что моральное, этическое знание необходимо человеку для того, чтобы стать добродетельным; указывается на важность различения жизни как таковой и жизни хорошей; обосновывается, что морально-этические принципы задают учителю исходную аксиому (во имя чего?) - во имя достижения цели - Мир на Земле, стратегию движения по избранному пути (каков путь?) - созидание добра для себя и для учащихся.

Ключевые слова: учитель; ученик; морально-этический принцип; добродетель; благо; идеал; ценность; добро; значение; мораль; нравственность; педагогическая рефлексия; поступок; взгляд; оценка; логика жизни; аксиома; стратегия; движение; осознание; нравственная жизнь.
\end{abstract}

Морально-этические принципы ориентируют учителя на совместный с учащимися поиск смысла жизни, который проясняет им отношения с миром, жизненный мир педагога и учащихся; существует в их сознании в виде образа мира, в форме смысловых структур; обеспечивает регуляцию их совместной деятельности в соответствии с логикой жизненной необходимости - Мир на Земле. Таким смыслом жизни и для учителя, и для учащихся, и для всех людей доброй воли в современной социально-нравственной ситуации являются добро и добродетель.

Морально-этические принципы, в терминологии Ю.А. Шрейдера, принципы этики являются «универсальными характеристиками ситуации морального выбора» $[1$, с. 26] и формулируются «в понятиях морального блага (как блага абсолютного) и моральной ценности» [1, с. 254]. 
«У морали, - пишет Г.К. Гумницкий, - нет полного согласия с жизнью, и это доказывается тем, что жизнь имеет своей целью полноту развития, совершенствование и счастье, а мораль непосредственной целью имеет добродетель, добро» [Цит. по: 2, с. 38]. Подлинная мораль считает человека и его жизнь, человечество высшими моральными ценностями, в которых формулируются морально-этические принципы, предписывающие выработку стратегии нравственной жизни. Высшими моральными ценностями являются и нравственные феномены добра, добродетели, чести, достоинства и др., обозначаемые определенными категориями, от правильного понимания которых, как подчеркивает Т.В. Мишаткина, «во многом зависит наша нравственность, наши поступки, взгляды, оценки» [3, с. 137].

Мы не осуществляем науковедческий анализ категорий «добродетель» и «добро», поскольку это является приоритетом этической науки. Однако полагаем необходимым заметить, что, если принять за аксиому, что истоки этики берут свое начало в Древней Греции, то категория «добродетель» является отправной для многих этических воззрений философов этой эпохи. В этой связи становится понятным, почему Г.К. Гумницкий указывает, что целью морали является добродетель и добро, а не добро и добродетель. Хотя, как мы полагаем, если сказать, что целью морали является добро и добродетель, то мы не погрешим истиной. Это объясняется тем, что творение, созидание добра причиняет становление добродетелей как нравственных качеств. Без добра нет и не может быть добродетели, которая есть «фундаментальное моральное понятие характеризующее готовность и способность личности сознательно и твердо следовать добру» $[4$, с. 116$]$.

При этом если категория «добро» от эпохи к эпохе имеет тенденцию наполняться новым содержанием и в принципе обладает общим смыслом для различных этических систем, то категория «добродетель» имеет несколько значений. Сказав, что добро в принципе обладает общим смыслом для различных этических систем, заметим, что, во-первых, добро в истории этической науки трактовалось как «удовольствие (гедонизм), польза (утилитаризм), счастье (эвдемонизм) и т.Д., иными словами, как то, что соответствует непосредственным (житейским) потребностям, интересам и ожиданиям человека как индивида и члена общества» [5, с. 113]; во-вторых, добро как высшая ценность обладает моральным, нормативно-ценностным содержанием, которое, естественно, в зависимости от социальных или иных изменений в ту или иную эпоху, менялось; в-третьих, добро выступает в качестве идеала нравственного поступка, деяния, совершенства человека. Все перечисленное выше не есть значения добра, а является различными его трактовками. Так, любая категория, в том числе и категория «добро», обладает значением ценности, идеала, словом, положительным смыслом, который и является общим для всех трактовок добра. То, что добро обладает значением ценности, идеала, не означает, что добро употребляется в различном значении.

Обладать значением и употребляться в различном значении не одно и то же. Употребление одного и того же понятия в различном значении означает, что оно имеет различные смыслы. В педагогике, например, категории «воспитание», «образование» и другие 190 категории употребляются в различном значении. Более того, различные педагогические теории и концепции, в центре внимания которых находится общая для них проблема образования, воспитания, обучения, поразному выстраивают свой понятийный аппарат. Так, например, в концепциях содержания образования, разрабатываемых И.Я. Лернером, М.Н. Скаткиным, В.В. Краевским и В.С. Ледневым во второй половине $\mathrm{XX}$ века, содержание образования конструируется на различных теоретико-методологических основаниях, на которых и выстраивается их понятийный аппарат. В концепции И.Я. Лернера, М.Н. Скаткина, В.В. Краевского в основу конструирования содержания образования положена идея о культуре как социальном опыте, выделение элементов которого становится основой для выделения структурных элементов содержания образования $[6$, с. $38 ; 7$, с. 10$]$, а само содержание образования строится на основе культурологического подхода. В основу концепции содержания образования В.С. Леднева положена идея о структуре личности и об инвариантных сторонах деятельности, о базисных компонентах личности и соответствующих им видам деятельности [8, с. 25-40, с. 73-80].

Категория «добродетель», как показывает анализ научной литературы, имеет ряд значений, а значит и смыслов. Так, Аристотель употреблял термин «добродетель» для обозначения качества [9, с. 63], а нравственная добродетель, согласно философу, - «это способность поступать наилучшим образом» [9, c. 82]. Категория «добродетель» употребляется и в других значениях. Парацельс, например, «употреблял понятие "добродетель" как синоним индивидуальных характеристик вещи, а именно ее особенности. Камень или цветок обладают каждый своей добродетелью, своей комбинацией присущих им качеств. Аналогичным образом и добродетель человека - это определенное множество качеств, характеризующих человека как вид, добродетель же каждого отдельного человека - это его уникальная индивидуальность» [Цит. по: 10, с. 28].

Э. Фромм, выявляя различия между авторитарной и гуманистической этикой, приходит к заключению, что в авторитарной этике понятие «добродетель» «означает самоотречение и послушание, подавление индивидуальности, а не ее полную реализацию» [10, c. 28]. Содержательный критерий гуманистической этики, как подчеркивает Э. Фромм, основан на принципе, что «"добро" есть то, что является благом для человека, а "зло" - то, что вредит ему. Единственный критерий этической ценности - это благополучие, благоденствие человека» [10, с. 28$]$.

Понятие «добродетель» в значении качества употребляет и А. Макинтайр: «Добродетель есть приобретенное человеческое качество» [11, с. 260].

Еще в одном значении понятие «добродетель» употребляет В.С. Соловьев: «Добродетельный человек есть человек, каким он должен быть. Другими словами, добродетель есть нормальное или должное отношение человека ко всему (ибо нельзя мыслить качеств и свойств безотносительных)» [12, с. 125]. Такое понимание В.С. Соловьевым добродетели означает, что в добродетели заключено фиксируемое ею содержание нравственного качества, понимание человеком мира и своего места в мире, своей позиции по отношению к миру и к людям. В деятельности, во взаимодействии с миром и с людьми проявляется 
добродетель или нравственное качество, в котором выражается и соответствующее ее содержанию отношение к миру и к людям.

Понимание В.С. Соловьевым добродетели как отношения ко всему, в том числе и к нравственным или безнравственным поступкам, к беззаконию, к двойным стандартам и т.д., дает нам основание утверждать, что добродетель есть ценность. Как ценность, она имеет значение для всех или большинства стремящихся к миру и к согласию людей и связывает человека с другими людьми. Данное утверждение основывается на том, что ценность, согласно М.С. Кагану, «предстает именно как отношение <..> поскольку она связывает объект не с другим объектом, а с субъектом, то есть носителем социальных и культурных качеств, которые и определяют сверхиндивидуальное содержание его духовной деятельности; деятельность человека и является реальным отношением» [13, с. 67]. В отношениях, образующих содержание деятельности учителя, как развиваются, так и проявляются добродетели или нравственные качества. Известно, что любая категория, в том числе и категория «добродетель», фиксирует отношение, а не свойства и качества, которые проявляются в отношениях. Категория «добродетель» фиксирует должное отношение, то есть такое, которое ждет своего осуществления.

Представление о содержании конкретных добродетелей как нравственных качеств человека также меняется от эпохи к эпохе.

В рамках античного морального канона, как подчеркивает А.А. Гусейнов, добродетель сопрягалась с мудростью и мудрецами, и для того чтобы быть добродетельным, надо знать, какие указания разума являются правильными [14, с. 325].

Так, тезис Сократа о том, что «добродетель есть знание» базируется на сопряжении разума и добродетели. Этот тезис, как подчеркивает А.А. Гусейнов, определяет нравственность как пространство ответственного поведения индивида, и если человек совершает зло и ясно понимает это, то он знает, чем зло отличается от добра [14, с. 325]. Добродетель у Сократа есть форма познания, назначением которой является совершенствование разума и души.

В учении Сократа о добродетели для педагогической науки значение представляют следующие идеи философа. Во-первых, это идея о том, что добродетели научить нельзя. В диалоге «О добродетели», Сократ в разговоре с другом о Перикле и о воспитании им своих сыновей Парала и Ксантиппа, заявляет, что «если бы добродетель была изучима и он (Перикл. A.C.) мог бы их сделать доблестными, гораздо раньше обучил бы их своей добродетели, чем музыке и состязаниям. Но оказалось, что добродетели, по-видимому, нельзя научить» $[15$, с. 356$]$. Добродетели воспитываются, они не являются врожденным. «Ни одна из нравственных добродетелей, - пишет Аристотель, не врожденна нам по природе, ибо все природное не может приучаться к чему бы то ни было» [9, с. 76]. Аналогичную точку зрения мы находим у Д. Локка, приведшего доказательства тому, что врожденных нравственных принципов нет, ибо они нуждаются в доказательстве [16, с. 114-134].

Если научить добродетели нельзя, то это не означает, что учителю, учащемуся не нужны знания о них как о нравственных качествах. Естественно, наличие знаний у учащихся не означает, что они всегда и вез- де совершают нравственные поступки. Власть разума не безгранична. Во власть разума верил Сократ. Он «пытался подчинить все, относящееся к человеческой жизни и ее ценностям, власти разума. И поскольку, для Сократа сама природа человека - это его душа, т.е. разум, а добродетели суть то, что совершенствует природу человека, то очевидно, что добродетели становятся формой познания» [17, с. 67].

Вместе с тем знания, как известно, обосновывают моральный выбор ценностей и поступков, имеют немаловажное значение в детерминации поведения, знания «составляют материала для выработки <..> уже сугубо личностных элементов» [18, с. 119].

Нельзя не привести в этой связи мысли Аристотеля и Гегеля об образовании. «На вопрос, какая разница между человеком образованным и необразованным, он (Аристотель. - А.С.) ответил: "Как между живыми мертвым"» [Цит. по: 19, с. 193]. Гегель пишет: «Чем образованнее человек, тем меньше выступает в его поведении нечто только ему свойственное и именно поэтому случайное» [20, с. 74]. Мы видим, что Гегель связывает образование с поведением человека, причем таким, в котором случайное уменьшается по мере обогащения сознания знанием в процессе воспитания как преобразования души. С момента поступления в школу «начинается жизнь согласно общему порядку, по одному, для всех одинаковому правилу; здесь дух должен быть приведен к отказу от своих причуд, к знанию и хотению общего, к усвоению существующего всеобщего образования. Только это преобразование души и называется воспитанием» $[20$, c. 74$]$.

Подтверждение тому, что знания необходимы человеку для того, чтобы стать добродетельным, нравственным, мы находим у А. Макинтайра, который полагает, что воспитание добродетелей или нравственных качеств сопряжено с поиском ответа на вопрос: «Можно ли рационально обосновать восприятие каждой человеческой жизни в виде некоторого единства, которое позволило бы каждой человеческой жизни обладать собственным благом? <..> Такое восприятие пролило бы новый свет на функцию добродетелей: они позволят индивиду предпочесть одно единство жизни другому» [11, с. 275].

Людей при достижении различных целей, в том числе и целей устранения угроз человечеству, человеку, объединяют добродетели как нравственные качества. В таком объединении людьми движут справедливость и милосердие, долг и ответственность и т.д., являющиеся не только категориями этики и понятиями морали, ценностями, но и нравственными качествами или добродетелями. Человек воспринимает другого человека с позиции проявляемых им в отношении к нему в поступках и действиях нравственных качеств, которые становятся объединяющей их силой.

Для педагогической науки в учении Сократа о добродетели значение представляет его идея о жизни хорошей. В диалоге «Критон» Сократ говорит: «Надобно дорожить не тем, что мы живем, а тем, что хорошо живем» [21, с. 79].

Разграничение между жизнью как таковой и жизнью хорошей, как подчеркивает А.А. Гусейнов, является исходной основой морального мировоззрения Сократа, и все усилия Сократа были посвящены поиску ответа на вопрос, какие убеждения являются 
наилучшими, какая жизнь - самой достойной. Развивая идеи Сократа о жизни хорошей или достойной жизни, А.А. Гусейнов подчеркивает, что «совершенный, добродетельный человек достоинство жизни ставит выше самой жизни» [22, с. 99]. Из этого следует, что самой достойной жизнью или жизнью хорошей является жизнь, в основании которой находится человеческое достоинство, жизнь, признающая достоинство другого.

Мы не можем со всей очевидностью утверждать, что идея Сократа о жизни как таковой и о жизни хорошей стала основой для Э. Фромма, разрабатывающего положения гуманистической этики, одним из ведущих среди которых является положение о тяге человека к жизни. «Человек не может не хотеть жить, независимо от того, что он думает по этому вопросу. Выбор между жизнью и смертью скорее кажущийся, чем реальный; реальный же выбор - это выбор между хорошей и плохой жизнью» [10, с. 32].

Мы написали, что «не можем со всей очевидностью утверждать», потому, что Э. Фромм не ссылается на Сократа и его мысли о жизни как таковой и жизни хорошей.

Морально-этическими принципами, в силу высокой степени их обобщенности, возможно руководствоваться везде и всегда. Они «передают культурные значения в самой абстрактной форме, указывая на сущность деятельности и задавая ее фундаментальные, ее последние основания» [23, с. 216], порождают «способность личности пользоваться своей свободой, то есть осознавать свою ответственность за другого, за его жизнь, его бытие» [23, с. 222].

Выше было отмечено, что принципы этики (мы будем говорить: «морально-этические принципы») формулируются «в понятиях морального блага (как блага абсолютного) и моральной ценности» [1, с. 26].

Понимание того, что морально-этические принципы формулируются в понятиях морального блага и моральной ценности влечет за собой необходимость раскрытия категорий «благо» и «ценность». Речь не идет о полноценном науковедческом анализе данных категорий, который осуществляется этической наукой.

Аристотель в своем учении о благе пишет, что «если у того, что мы делаем, существует некая цель, желанная нам сама по себе, причем остальные цели желанны ради нее и не все цели мы избираем ради иной цели $<\ldots>$ то ясно, что цель эта есть собственно благо, т.е. наивысшее благо» [9, с. 54-55]. Согласно Аристотелю, благом является не просто цель, но желанная цель, то есть такая цель, которую человек стремится достичь, а самая совершенная цель и есть искомое благо. Р.Г. Апресян уточняет: «То, что ценно для человека как такового вообще и отвечает его назначению, Аристотель назвал высшим благом» [24, c. 230]. То, что ценно для человека, есть ценность. Это означает, что категория «благо» употребляется в значении ценности как нечто значимого для него. В самом широком смысле, пишет Р.Г. Апресян, «ценностями называются обобщенные, устойчивые представления о чем-то предпочтительном, как о благе, т.е. о том, что отвечает каким-то потребностям, интересам, намерениям, целям, планам человека (или группы людей, общества)» [24, с. 228].

Точку зрения близкую точке зрения Р.Г. Апресяна о том, что благо есть ценность, мы находим у Н. Гартмана: «Всякая действующая мораль говорит о 192 благе как о чем-то известном. Фактически под благом она всегда подразумевает лишь некую определенную ценность, частную ценность, которую она считает единственной и высшей» [25, с. 369].

Итак, одним из значений блага является ценность. Следовательно, выбор учителем блага для себя и для учащихся, для взаимодействующих с ним людей, есть выбор нравственной ценности, иными словами, добра. В.С. Соловьев, рассуждая о единстве нравственных основ, поставил вопрос о соотношении добра и блага. Суть такого соотношения заключается в том, что понятия «добро» и «благо» взаимосвязаны, между ними нет никакого противоречия, что благо есть другая сторона добра: «Нравственная ценность добро по самому существу своему есть способ действительного достижения блага <...> т.е. такового, которое может дать человеку устойчивое и окончательное удовлетворение. Благо (и блаженство) в этом смысле есть только другая сторона добра, или другая точка зрения на него, - между этими двумя понятиями такая же внутренняя связь и такая же невозможность противоречия, как между причиной и следствием, целью и средством и т.П.» [12, с. 166].

Другим значением блага, как показывает анализ научной литературы, является идеал: «В современной аксиологии и этике высшее благо называют идеалом» [24, c. 230].

При этом категория «идеал» употребляется учеными в значении ценности. Согласно Е.Л. Дубко и В.А. Титову, «идеал представляет собой обобщенное представление о максимально возможном уровне распространения и реализации моральных ценностей» $[26$, c. 8]. Ставя вопрос о происхождении идеалов, М.С. Каган отмечает, что «стоит нам увидеть в них модели "потребного будущего", и станет ясным, что идеал конкретно, в представлении, воплощает то, что обладает для субъекта ценностью» [13, с. 186].

Мы не приводим имеющиеся в науке определения вышеперечисленных категорий. Наша задача состоит не в перечислении определений категорий «блага», «добродетель», «идеал», «ценность», не в выявлении общего и различного во взглядах ученых относительно понимания ими содержания данных категорий, а в выявлении значений данных категорий. Это, вопервых. Во-вторых, мы привлекаем данные категории для того, чтобы стало понятным, почему моральноэтические принципы будут формулироваться в понятии моральной ценности, значением которой, как было установлено выше, обладают благо, добро, добродетель, идеал.

Заметим, что различные определения категории «идеал» приведены в работах Л.В. Вершининой [27, c. 43-45], Ю.В. Лопуховой [28, с. 94-98] и других тематически близких к нашей работе педагогических исследованиях. При этом ученые приводят определения идеала при решении других, чем мы, задач. Так, Л.В. Вершинина осмысливает содержание данной категории в целях выявления структуры ценностного сознания учителя, Ю.В. Лопухова - в целях выявления признаков, которым отвечает толерантность как моральный идеал, являющийся определяющим для оценки глобализирующегося общества.

Различные определения категории «ценность» приведены в работах А.В. Бездухова [29, с. 99-101], 
Ю.В. Лопуховой $[28$, с. $72-73]$ и других ученых. А.В. Бездухов, например, обращается к проблеме ценностей с целью раскрытия сущности ценностного подхода к формированию гуманистической направленности будущего учителя, Ю.В. Лопухова - с целью выявления признаков, которым отвечает толерантность как ценность.

Морально-этические принципы задают учителю исходную аксиому (во имя чего?) - во имя достижения цели - Мир на Земле, стратегию движения по избранному пути (каков путь?) - созидание добра для себя и для учащихся, которые, став взрослыми, консолидируются вокруг ценностей и идеалов в целях решения глобальных проблем современности, предотвращения угроз национальной безопасности государства, общества и личности в лице терроризма, влекущего за собой человеческие жертвы, разрушающего личность человека, культурное наследие, порождающего ненависть и недоверие к этносам, социальным группам.

\section{СПИСОК ЛИТЕРАТУРЫ:}

1. Шрейдер Ю.А. Этика. М.: Текст, 1998. 271 с.

2. Кобляков В.П. Этическое сознание. Л.: ЛГУ, 1979. 222 c.

3. Мишаткина Т.В. Высшие моральные ценности и стратегия «правильной жизни» // Этика: учебное пособие / под ред. Т.В. Мишаткиной, Я.С. Яскевич. Минск: Новое знание, 2002. С. 129-264.

4. Гусейнов А.А. Добродетель // Этика: энциклопедический словарь / под ред. Р.Г. Апресяна, А.А. Гусейнова. М.: Гардарики, 2001. С. 116-118.

5. Апресян Р.Г. Добро // Этика: энциклопедический словарь / под ред. Р.Г. Апресяна, А.А. Гусейнова. М.: Гардарики, 2001. С. 113-115.

6. Лернер И.Я. Дидактические основы методов обучения. М.: Педагогика, 1981. 186 с.

7. Краевский В.В. Чему учить? // Вопросы образования. 2004. № 3. С. 5-23.

8. Леднев В.С. Содержание общего среднего образования: проблемы структуры. М.: Педагогика, 1980. $264 \mathrm{c}$.

9. Аристотель. Сочинения. В 4 т. Т. 4. М.: Мысль, $1983.830 \mathrm{c}$.

10. Фромм Э. Психоанализ и этика. М.: Республика, 1993.416 с.

\section{MORAL AND ETHICAL PRINCIPLES AS AN OBJECT OF PEDAGOGICAL REFLECTION} (C) 2016

\section{A.I. Salov, candidate of pedagogical sciences, associate professor, rector Academy of Public Administration, Moscow (Russia)}

Abstract. The paper grounds that moral and ethical principles guide the teacher to seek the meaning of life together with the students which explains to them the relations with the world, provides insight into the teacher's and students' world, exists in their mind as a world image and regulates their mutual activity in accordance with the logics of life necessity, i.e. Peace on the Earth. The author explains that the true morality considers a person and his/her life the most important moral values, which formulate moral and ethical principles, prescribing development of moral life strategy. The paper proves that person's morality, his/her doings, outlook, evaluation, goals and motifs of activity and relations with people and the world depend on correct understanding of values. The author explains the categories «virtue», «good», in terms of which moral and ethical principles are formulated. The paper gives the meaning of the categories «virtue» and «good» and explains why one cannot teach virtue, that virtues are not inherent that is why they are nurtured. The author shows moral and ethical knowledge is necessary for a person to become virtuous and points out the importance of differentiation between life as it is and good life. The paper grounds that moral and ethical prin- 
ciples provide a teacher with an initial axiom (what for?) - for achieving the goal - Peace on the Earth, the strategy of moving along the way chosen (what way?) - making good for him/herself and for the students.

Keywords: teacher; student; moral and ethical principle; virtue; good; ideal; value; goodness; meaning; morality; ethics; pedagogical reflection; action; opinion; evaluation; the logic of life; axiom; strategy; movement; awareness; moral life.

УДК 378:37.036.5

\title{
РАЗВИТИЕ ТВОРЧЕСКОЙ АКТИВНОСТИ СТУДЕНТОВ ВУЗА КАК ПЕДАГОГИЧЕСКАЯ ПРОБЛЕМА
}

(C) 2016

E.P. Стаценко, кандидат педагогических наук, доцент, декан факультета искусств и сервиса Мурманский арктический государственный университет, Мурманск (Россия)

\begin{abstract}
Аннотащия. В статье проблема развития творческой активности студентов обосновывается как актуальная социально-педагогическая проблема. Аргументируется роль понятий «творчество» и «активность» как понятий, несущих равную смысловую нагрузку в понятии «творческая активность». Творчество рассматривается как продуктивная форма активности и самостоятельности человека, делается акцент на взаимосвязи творчества и новизны. Обосновывается, что деятельность человека и его активность предполагают друг друга, что активность человека, как проявление его жизненных сил, является как предпосылкой, так и результатом его развития. Утверждается, что на репродуктивно-подражательном уровне активности человек накапливает опыт деятельности, обращаясь к опыту другого человека; на поисково-исполнительском - принимает задачу и самостоятельно ищет пути ее выполнения; на творческом - сам ставит задачу и избирает новые, нешаблонные, оригинальные пути ее решения. Обосновывается, что творческая активность студента вуза представляет собой качество деятельности личности, проявляемое в отношении студента к содержанию и процессу деятельности, в его стремлении к успешному овладению знаниями и способами деятельности, в мобилизации нравственноволевых усилий на достижение цели деятельности. Приводятся характеристики творческой активности студента вуза. Рассматриваются формы, методы и средства развития творческой активности студентов. Доказывается эффективность использования проектной студии как формы развития творческой активности студентов вуза. Приводятся примеры работы проектной студии на факультете искусств и сервиса. Обозначаются принципы развития творческой активности студентов, реализуемые в работе проектной студии.

Ключевые слова: студент; вуз; творчество; активность; творческая активность; развитие; уровни активности личности; форма; метод; средство; проектная студия; принципы развития творческой активности; принцип целеполагания; принцип доступности; принцип индивидуализации.
\end{abstract}

Среди реалий современного российского общества важное место занимают инновационные процессы во всех его сферах. Осуществление таких процессов требует не только специальной профессиональной подготовки человека к деятельности в той или иной области науки, техники, производства, но и формирования личности, готовой как эффективно осваивать, так и продуцировать новое знание, осуществлять творческий подход к своей жизни и деятельности. Тем самым сегодня особое значение приобретает проблема воспитания творческой личности, развития творческой активности человека, что предполагает вхождение человека в мир творчества, формирование у него способности к преобразованию действительности, к творческому поиску чего-то нового, не бывшего ранее.

Проблема формирования творческой активности это далеко не новая научная проблема. Данное понятие уже приобрело статус междисциплинарной категории и разрабатывается как психологами, так и педагогами. Д.Б. Богоявленская [1], А.В. Брушлинский [2], Л.С. Выготский [3], Ю.Н. Кулюткин и Г.С. Сухобская [4], А.Н. Лук [5], А.М. Матюшкин [6], Я.А. Пономарев [7], С.Л. Рубинштейн [8], М.Г. Якобсон [9]; В.И. Андреев [10], И.П. Волков [11], В.И. Загвязинский [12], Г.И. Щукина [13] и другие известные ученые в разной мере уделяли внимание проблеме творчества в целом и творческой активности личности в частности. Обращение к научной периодике последних лет показывает, что данная проблема остается в центре внимания современных исследователей. Заметим, что при изучении творческой активности мы сконцентрировали внимание на творческой активности студентов вузов. Данной проблеме посвящены статьи С.М. Варнавских [14], Н.К. Джамирзе [15], Л.В. Ивановой [16], О.Л. Раковской [17], В.П. Строкова [18], Н.В. Тальтевской [19], Б.К. Укуевой [20], Н.В. Филисюк [21], И.В. Фуфаева [22] и др.

Смысловую нагрузку в понятии «творческая активность» в равной мере несут и понятие «творчество» и понятие «активность».

Обращение к научной литературе показывает, что творчество представляет собой продуктивную форму активности и самостоятельности человека. Результатом творчества «являются научные открытия, изобретения, создание новых музыкальных, художественных произведений, решение новых задач в труде врача, учителя, художника, инженера и т.д.» [23, с. 421].

Культура, наука, искусство, человеческая цивилизация в целом - все создано творчеством. Повседневный труд также предполагает творчество. Именно в творческом подходе к труду естественно, полноценно выражаются человеческие возможности.

В классическом понимании учеными творчества делается акцент на взаимосвязи творчества и новизны - творчество предполагает создание нового. Так, по 